\title{
Hepatitis B virus induces sorafenib resistance in liver cancer via upregulation of clAP2 expression
}

\author{
Shouhua Zhang ${ }^{1,2 \dagger}$, Nuoya $\mathrm{Li}^{1 \dagger}$, Yanling Sheng ${ }^{3}$, Wen Chen ${ }^{4}$, Qiangliang $\mathrm{Ma}^{5}$, Xin Yu' ${ }^{1}$ Jianping Lian ${ }^{6}$, \\ Junquan Zeng ${ }^{6}$, Yipeng Yang ${ }^{7 *}$ and Jinlong Yan $^{1 *}$ (D)
}

\begin{abstract}
Background: HBV promotes cell survival by upregulating the expression of the cellular inhibitor of apoptosis protein 2 (CIAP2), however whether it is involved in HBV-induced sorafenib resistance in liver cancer remains unclear.
\end{abstract}

Methods: CIAP2 overexpression and knockdown was adopted to assess the involvement of CIAP2 in HBV-induced sorafenib resistance. Anti-HBV drug lamivudine and Akt inhibitor were used to investigate the impact of HBV replication on CIAP2 expression and sorafenib resistance. Xenotransplantation mouse model was used to confirm the data on cell lines in vitro.

Results: Liver cancer cell line HepG2.215 showed increased cIAP2 expression and enhanced resistance to sorafenib. Upon sorafenib treatment, overexpression of CIAP2 in HepG2 lead to decreased cleaved caspase 3 level and increased cell viability, while knockdown of cIAP2 in HepG2.215 resulted in increased level of cleaved caspase 3 and decreased cell viability, suggesting the involvement of CIAP2 in HBV-induced sorafenib resistance. Furthermore, antiHBV treatment reduced cIAP2 expression and partially restored sorafenib sensitivity in HepG2.215 cells.

Xenotransplantation mouse model further confirmed that co-treatment with lamivudine and sorafenib could reduce sorafenib-resistant HepG2.215 tumor cell growth.

Conclusion: CIAP2 is involved in HBV-induced sorafenib resistance in liver cancer and anti-HBV treatments reduce CIAP2 expression and partially restore sorafenib sensibility.

Keywords: Hepatitis B virus, CIAP2, Sorafenib resistance, Liver cancer, Lamivudine

\section{Background}

Liver cancer is one of the most prevalent cancers in the world and also a leading cause of cancer-related death worldwide, resulting in about 841,000 new cases and more than 780,000 deaths every year $[1,2]$. Although

\footnotetext{
*Correspondence: yangyipeng@xinhuamed.com.cn; yj119880608@126.com

†Shouhua Zhang and Nuoya Li contributed equally to this work.

${ }^{7}$ Department of General Surgery, Xinhua Hospital of Shanghai Jiao Tong University School of Medicine, 1665 Kongjiang Rd, Shanghai, China

'Department of General Surgery, Second Affiliated Hospital of Nanchang University, 1 Minde Road, Nanchang, Jiangxi, China

Full list of author information is available at the end of the article
}

there are various risk factors for liver cancer, chronic infections with hepatitis B virus (HBV) are estimated to be responsible for at about $50 \%$ of cases in the world [3, 4]. HBV infection is one of the most common infections worldwide, with approximately $3.5 \%$ ( 257 million) of the world's population are chronically infected with HBV and $10-25 \%$ of the HBV carriers have the lifetime risk of dying of either liver cancer or cirrhosis [5].

Currently, surgical resection, liver transplantation and radiofrequency ablation are the major treatment modalities for early stage liver cancer, while treatment options

C C The Author(s). 2021 Open Access This article is licensed under a Creative Commons Attribution 4.0 International License, which permits use, sharing, adaptation, distribution and reproduction in any medium or format, as long as you give appropriate credit to the original author(s) and the source, provide a link to the Creative Commons licence, and indicate if changes were made. The images or other third party material in this article are included in the article's Creative Commons licence, unless indicated otherwise in a credit line to the material. If material is not included in the article's Creative Commons licence and your intended use is not permitted by statutory regulation or exceeds the permitted use, you will need to obtain permission directly from the copyright holder. To view a copy of this licence, visit http://creativecommons.org/licenses/by/4.0/ The Creative Commons Public Domain Dedication waiver (http://creativecommons.org/publicdomain/zero/1.0/) applies to the data made available in this article, unless otherwise stated in a credit line to the data. 
for advanced disease are very limited because conventional systemic chemotherapy has little effect [6]. Unfortunately, patients are mostly diagnosed in the advanced stage, with the 5-year survival rate less than 20\% [7]. Up to now, sorafenib, a multitarget tyrosine kinase inhibitor, is the first and one of the few US FDA approved chemotherapy agents for advanced liver cancer [8]. Although sorafenib showed improved overall survival of patients with advanced liver cancer, its therapeutic effects are modest and also affected by several factors like HBV infection [9]. Clinical trials have suggested that liver cancer patients with HBV infection do not respond well to sorafenib than HBV negative liver cancer patients, indicating HBV may be able to induce sorafenib resistance in liver cancer via certain not yet known mechanisms [10].

Our previous study has shown that HBV infection can significantly induce the expression of the cellular inhibitor of apoptosis protein 2 (cIAP2) in liver cells via PI3K/ Akt/NF-kB signaling pathway [11]. This finding implies that $\mathrm{HBV}$ promotes liver carcinogenesis through the modulation of cIAP2 expression. Since cIAP2 is a protein that supports cell survival by inhibiting cell apoptosis, whether it is involved in HBV-induced sorafenib resistance in liver cancer remains to be clarified. In this study, we aimed to investigate this question and also the possible underlying mechanism and potential strategies to overcome HBV-associated sorafenib resistance in liver cancer.

\section{Materials and methods}

\section{Animals and ethical statement}

Female BALB/c nude mice aging from 4 to 5 weeks were purchased from Beijing HFK Biotechnology and housed in specific pathogen-free condition with sterilized food, water and bedding provided. All experimental protocols involving animals were reviewed and approved by the Ethical Review Committee of Second Affiliated Hospital of Nanchang University (Approval Number: 2018083) and performed in accordance with the local regulations.

\section{Plasmids and cell lines}

The following plasmids were used in this study. Mammalian expression vector pcDNA3.1(+) was purchased from ThermoScientific. To construct the cIAP2-expressing plasmid (p-cIAP2), cIAP2 coding sequence was obtained from Genebank (Accession number: NM_001165.5) and synthesized by GenScript Biotech and subcloned into pcDNA3.1(+).

Non-HBV expressing human liver cancer cell line HepG2 and persistent HBV-expressing liver cancer cell line HepG2.215 were both purchased from the American Type Culture Collection and cultured in DMEM with $10 \%$ FBS and antibiotics.

\section{Cell transfection and drug treatments}

For plasmid transfection, HepG2 cells preseeded in 12 well plates were either untransfected or transfected with empty vector pcDNA3.1(+) or p-cIAP2, using Lipofectamine 2000 (Thermo Scientific) according to the manufacturer's instructions. For siRNA transfection, HepG2.215 cells preseeded in 12 well plates were either untransfected, or transfected with control siRNA $(4,390,844$, Thermo Scientific) or cIAP2 siRNA $(4,392,420$, Thermo Scientific) both at the final concentration of $10 \mathrm{nM}$, using MISSION siRNA Transfection Reagent (Sigma-Aldrich) according the manufacturer's instructions. Cells were either further treated with sorafenib or harvested as follows. For western blot analysis, cells were harvested $48 \mathrm{~h}$ post transfection, while for sorafenib treatment and cell viability assay, sorafenib at a final concentration of $7.5 \mu \mathrm{M}$ was added $24 \mathrm{~h}$ post transfection and cell viability was assessed $48 \mathrm{~h}$ post sorafenib addition. For cells receiving lamivudine treatment, lamivudine at the final concentration of $100 \mu \mathrm{g} / \mathrm{ml}$ was added to cell culture for one week before cell seeding into plates.

\section{Cell viability assay}

Cell viability was assessed using the MTT Cell Proliferation/Viability Assay Kit (R\&D systems) according to the manufacturer's instructions. In brief, MTT reagent at the dilution of 1:10 was added into cell culture and incubated for $4 \mathrm{~h}$ when purple precipitate was visible under the microscope. Then equal volume of Detergent Reagent was added to the medium and the plate was incubated for another $4 \mathrm{~h}$ in the dark. After incubation, Absorbance was measured with the testing wavelength of $570 \mathrm{~nm}$ and the reference wavelength at $650 \mathrm{~nm}$. Cell viability was calculated with untreated cells being considered as $100 \%$ viable.

\section{Western blot}

Western blot was conducted as previously described with modifications [12]. In brief, cells were harvested and lysed using Pierce ${ }^{\mathrm{Tw}}$ IP Lysis Buffer (Thermo Scientific) supplemented with protease inhibitor cocktail (Roche). Cell lysate was then centrifuged at $10,000 \mathrm{~g}$ for $10 \mathrm{~min}$ to remove insoluble. Cleared cell lysate supernatant was resolved by a 4-12\% SDS-PAGE gel and transferred onto a PVDF membrane. After transfer, the membrane was sequentially blocked with $5 \%$ nonfat milk for $1 \mathrm{~h}$ at room temperature, incubated with primary antibodies overnight at $4{ }^{\circ} \mathrm{C}$, and with HRP-conjugated secondary antibodies for $1 \mathrm{~h}$ at room temperature. Three washes with PBST was done between incubations, and after the final wash, immuobands on the membrane was developed by ECL Plus Western Blotting Substrate (BosterBio) and imaged by ChemiDoc XRS + System (BioRad). Band intensity was quantified by Image J (version 1.53c, National Institute of Health, USA). 


\section{Quantification of HBV DNA}

Quantification of HBV DNA was performed as previously described with modifications [11]. In brief, DNA was extracted from cell culture supernatant using QIAamp DNA Mini Kit (Qiagen) and HBV DNA was quantified by TaqMan RT-PCR using SsoAdvanced ${ }^{\text {mx }}$ Universal Probes Supermix (Bio-Rad) on a Bio-Rad CFX96 platform. The following primers were used: forward primer: $5^{\prime}$-TTCCTCTCATCCTGCTGC-3', reverse primer: 5'-ACAAACGGGCAACATACCTTG-3', and TaqMan probe FAM-TATGCCTCATCTTCTTRT TGGTT. $\beta$-actin was used in our study as a normalization control for the quantification of HBV DNA. The following primers were used: forward primer: 5 ' - AGGTGAGGCT GCAAACAGCTA-3', reverse primer: 5' - TGAATCCT TTTCTGAGGGATGAA-3', and TaqMan probe FAMTGCACATTGGCAACAGCCCCTG. The thermocycling program was set as follows: polymerase activation and DNA denaturation: $95^{\circ} \mathrm{C}, 3 \mathrm{~min} ; 40$ cycles of $95^{\circ} \mathrm{C}, 15 \mathrm{~s}$ (denaturation) and $60^{\circ} \mathrm{C}, 15 \mathrm{~s}$ (annealing and extension).

\section{Tumor cell injection and drug treatments}

Tumor development in nude mice was performed as previously described with modifications [13]. In brief, HepG2 and HepG2.215 cells were harvested and washed with PBS and then resuspended at $2 \times 10^{7}$ cells $/ \mathrm{ml}$ in PBS. Each mouse was received $300 \mu \mathrm{l}$ cells subcutaneously at the left flank. Drug treatment started when tumor volume reached around $100 \mathrm{~mm}^{3}$. Both sorafenib (prepared in $0.4 \%$ DMSO in PBS) and lamivudine (prepared in PBS) were injected at the dose of $100 \mathrm{mg} / \mathrm{kg}$ intraperitoneally once a day for 15 consecutive days. For the animals missing one or both of the drugs, mock treatment with solvent (0.4\% DMSO in PBS for sorafenib and PBS for lamivudine) in the same volume was injected.

\section{Measurement of tumor volume, tumor weight and animal weight}

Tumor size was measured every 3 days and tumor volume was calculated using the formula: $V=(\text { mean diameter })^{3}$ $\times \frac{\pi}{6}$, as previously described [14]. Animal weight was also measured every 3 days. Tumor weight was measured on the day of animal sacrifice.

\section{Statistical analysis}

All statistical analyses in this study was performed using GraphPad Prism 8.3.0 (GraphPad) and all numerical data were presented as mean \pm standard deviation (SD). For comparisons between two groups, Mann-Whitney test was used, whereas for comparisons among three or more groups, One-way ANOVA with Dunn's multiple comparison test were adopted. For all the analyses, a $p$ value less than 0.05 was considered significant.

\section{Results \\ HBV infection induces resistance to sorafenib in liver cancer cells}

HBV infection induces resistance to sorafenib in liver cancer, but the underlying mechanism remains unclear. Our previous study showed that HBV infection significantly induced the expression of an anti-apoptotic protein, cIAP2 [11]. Whether the upregulation of cIAP2 contributes to the sorafenib resistance in HBV-infected liver cancer remains to be investigated.

We used HBV-producing liver cancer line HepG2.215 and its parental non-HBV liver cancer cell line HepG2 as our in vitro models. First, we confirmed that cIAP2 expression was upregulated upon HBV infection in liver cancer cells (Fig. 1a). Next, we also tested the sensitivity of the two cell lines to sorafenib. Both HepG2 and Hep2.215 were treated with ascendant concentrations of sorafenib and the cell viability was assessed by MTT assay and cleaved caspase 3 expression. Our data showed that HepG2 was significantly more sensitive to sorafenib treatment than HepG2.215, as evidenced by MTT (Fig. 1b) and cleaved caspase 3 expression (Fig. 1c). In addition, the expression levels of cIAP2 in both HepG2 and HepG2.215 cells were determined after treatment with various doses of sorafenib and no apparent change was observed, indicating sorafenib treatment does not affect cIAP2 expression (Fig. 1c). Together, these data here indicate that HBV infection could upregulate cIAP2 expression, and also induce liver cancer cell tolerance to sorafenib.

\section{clAP2 expression is associated with sorafenib resistance in liver cancer cells}

To further explore whether cIAP2 expression is associated with sorafenib resistance in liver cancer cells, HepG2 cells were transfected with p-cIAP2 to overexpress this protein and their sensitivity to sorafenib were assessed. As shown in Fig. 2a, when cIAP2 was overexpressed in HepG2 cells, the level of cleaved caspase 3 was considerably decreased. Similarly, sorafenib-induced cell death was significantly decreased in HepG2 cells with cIAP2 overexpression, comparing to those transfected with pcDNA3.1 (Fig. 2b). By contrast, HepG2.215 cells, when transfected with cIAP2 siRNA, showed higher level of cleaved caspase 3, comparing to cells transfected with control siRNA (Fig. 2c). Similarly, HepG2.215 cells with cIAP2 knockdown became significantly more sensitive to sorafenib, comparing to cells without cIAP2 knockdown (Fig. 2d). In addition, cIAP2 siRNA transfection only downregulated cIAP2 expression, without showing any apparent effect on the level of 


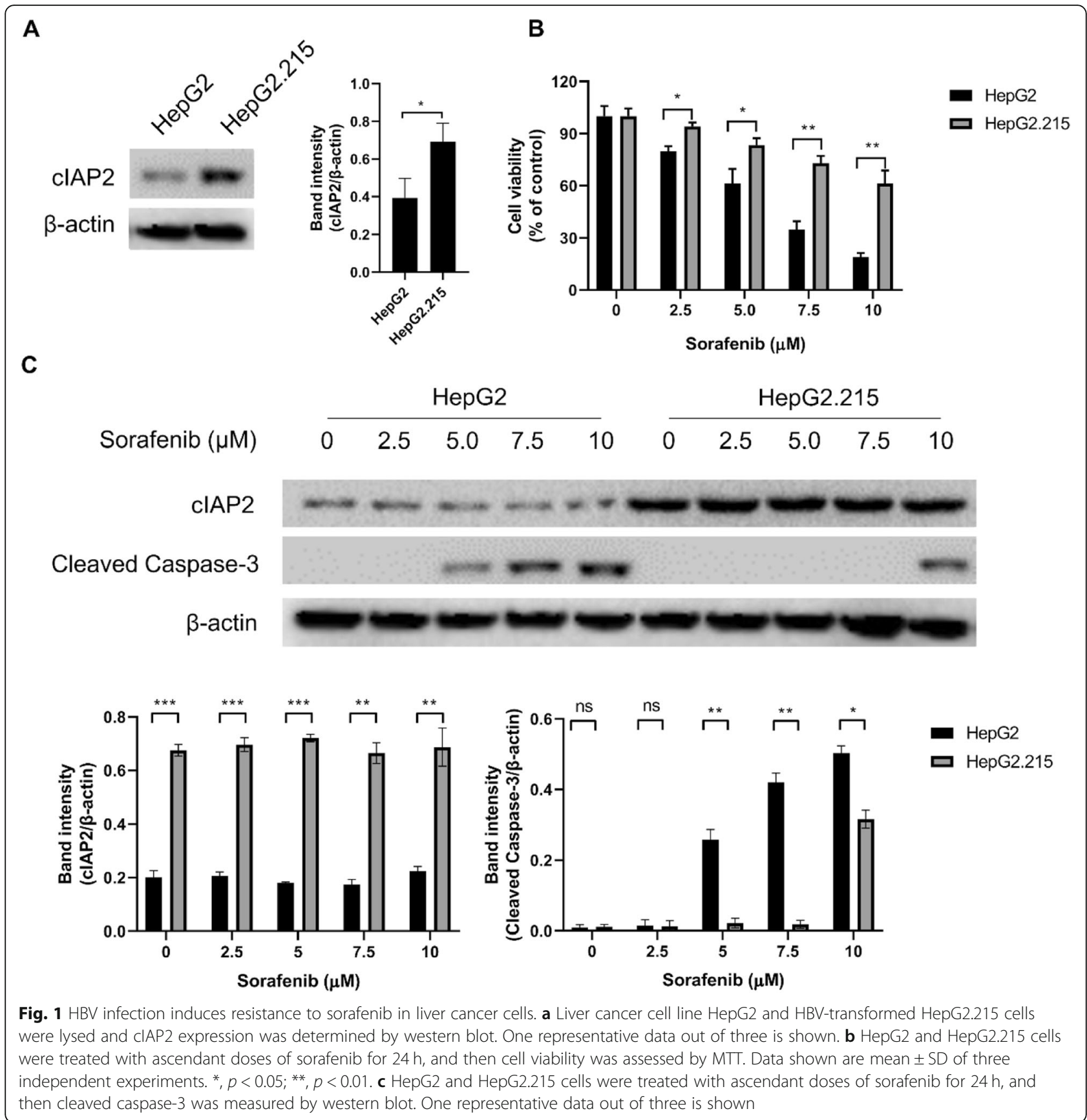

cleaved Caspase-3 and cell viability (Fig. 2c and d). Taken together, our data here indicate that cIAP2 expression is involved in the resistance of liver cancer cells to sorafenib.

Anti-HBV treatment with lamivudine reduces CIAP2 expression and partially restores sensitivity to sorafenib in liver cancer cells

Since HBV induces cIAP2 expression and cIAP2 expression is associated with sorafenib resistance in liver cancer cells, we further investigated whether inhibition of HBV replication would impact cell sensitivity to sorafenib. HepG2.215 cells were first treated with or without anti-HBV drug lamivudine, and then cell sensitivity to sorafenib was assessed. Treatment with lamivudine could reduce cIAP2 expression (Fig. 3a) and HBV replication (Fig. 3b), but did not induce cleaved caspase 3 expression (Fig. 3 a). Interestingly, after lamivudine treatment, cells became more sensitive to sorafenib, as evidenced by cleaved caspase 3 expression (Fig. 3a) and cell viability (Fig. 3c). 
A

HepG2

\begin{tabular}{|c|c|c|c|c|c|}
\hline Sorafenib & - & + & & & - \\
\hline pcDNA3.1 & - & - & & & - \\
\hline p-clAP2 & - & - & & - & + \\
\hline
\end{tabular}

Cleaved Caspase-3

$\beta$-actin

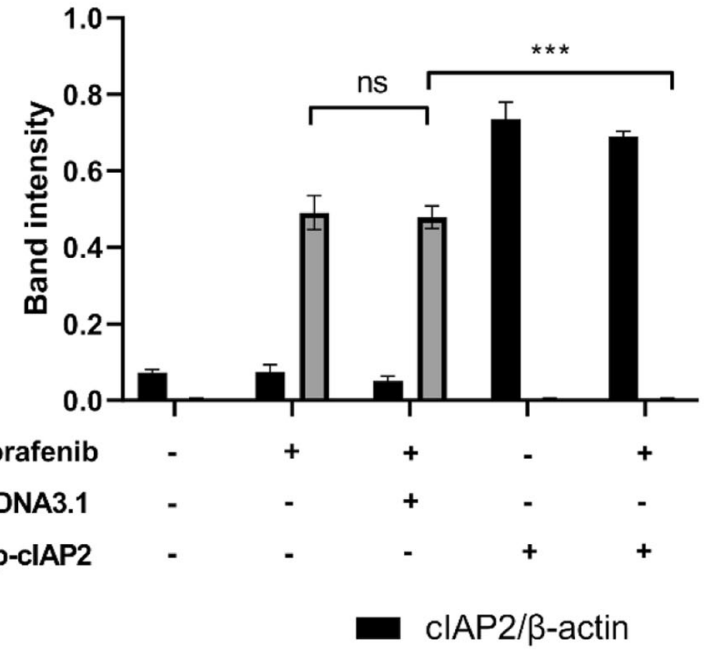

B

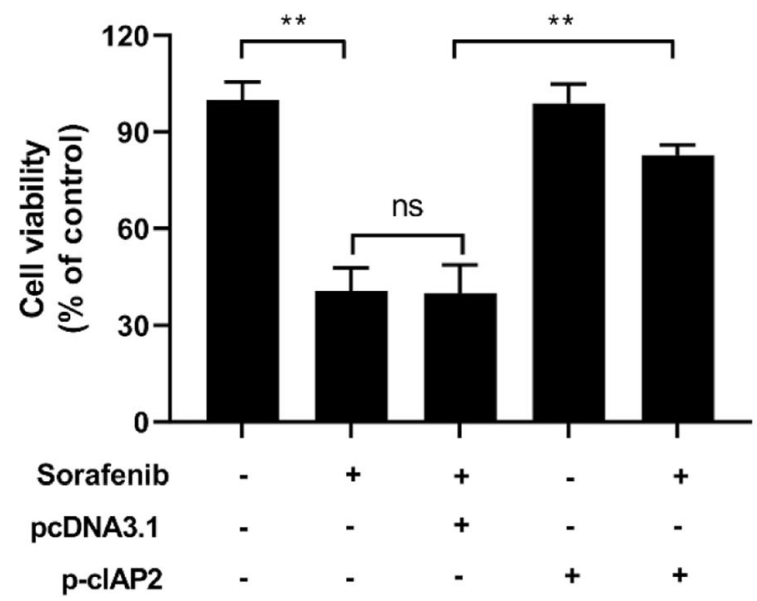

C

HepG2.215

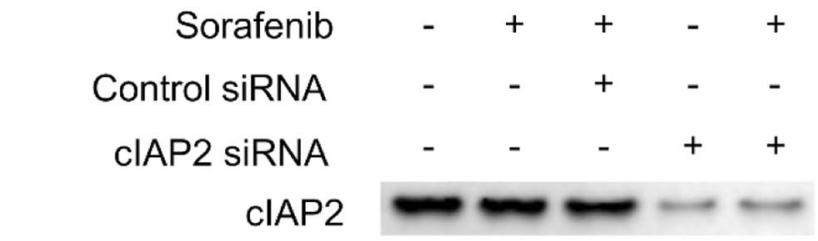

Cleaved Caspase-3

$\beta$-actin

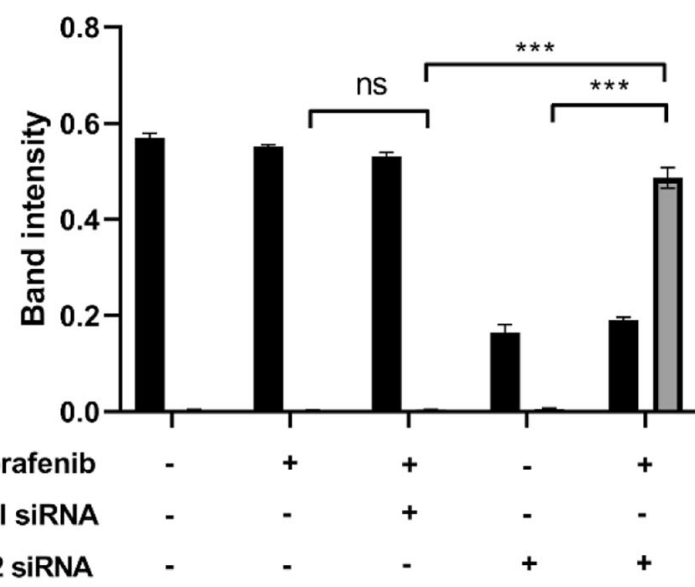

Cleaved Caspase-3/ $\beta$-actin

D

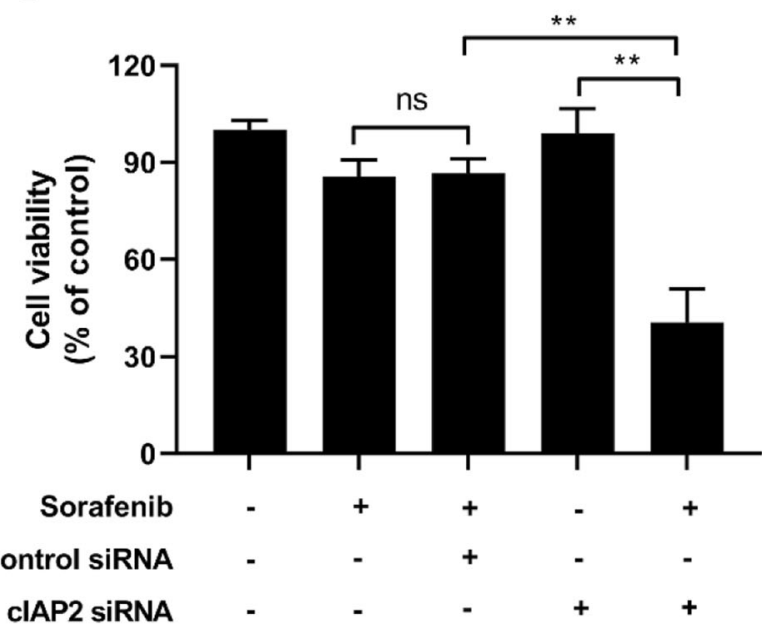

Fig. $\mathbf{2}$ CIAP2 expression is associated with sorafenib resistance in liver cancer. a-b HepG2 cells were first transfected with pcDNA3.1 or p-cIAP2, and then treated with sorafenib. c-d HepG2.215 cells were first transfected with control siRNA or CIAP2 siRNA, and then treated with sorafenib. Twenty-four $\mathrm{h}$ later, $\mathbf{a}$ and $\mathbf{c}$ the expression of CIAP2 and cleaved caspase- 3 were measured by western blot, $\mathbf{b}$ and $\mathbf{d}$ cell viability was determined by MTT. For western blot, one representative data out of three is shown. For cell viability, data shown are mean \pm SD of three independent experiments. ns, not statistically significant; ${ }^{*}, p<0.05 ;{ }^{* *}, p<0.01$ 


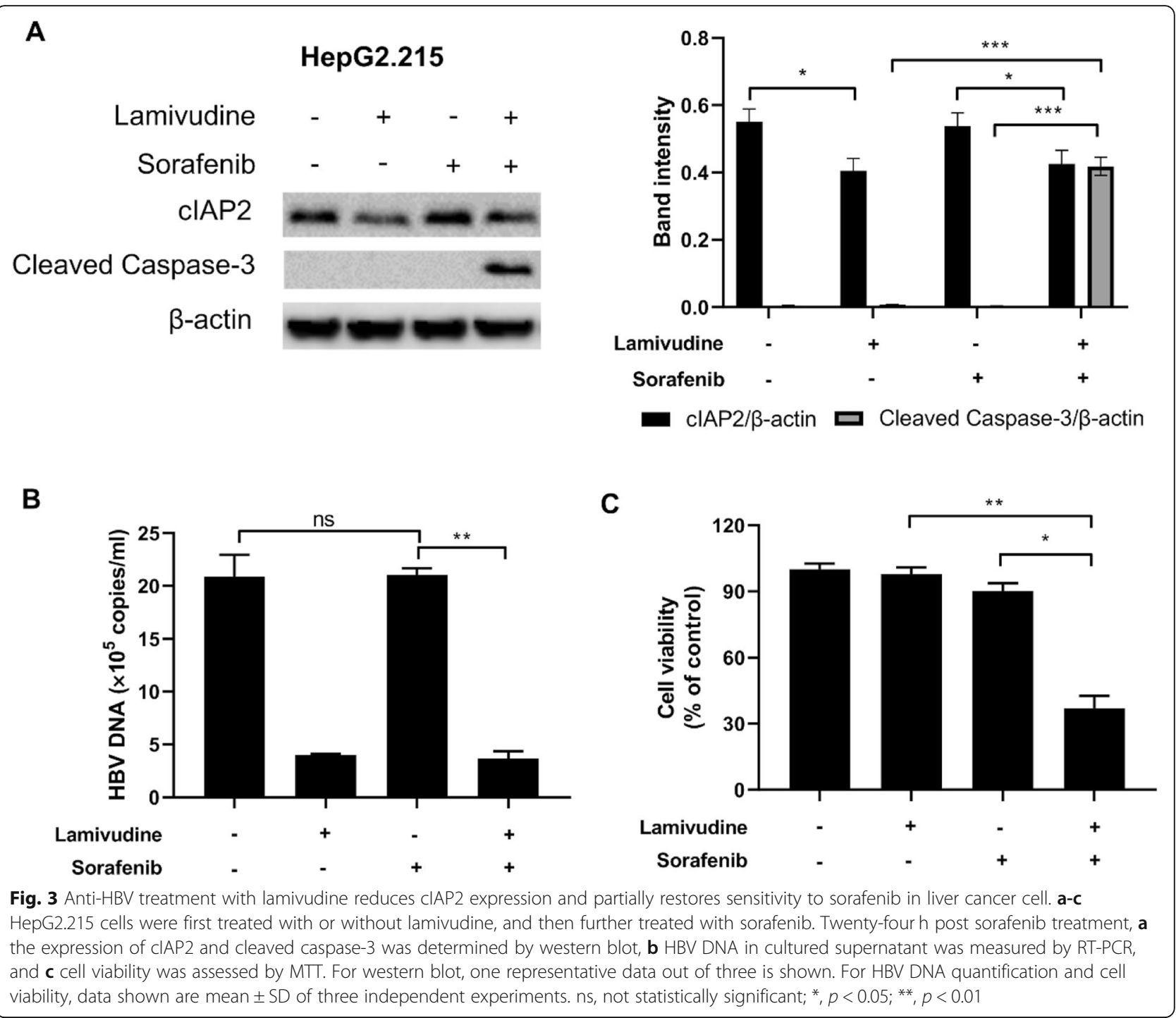

Akt inhibitor treatment reduces cIAP2 expression and partially restores sorafenib sensitivity in liver cancer cells Our previous study showed that HBV infection induced cIAP2 expression via PI3K/Akt/NF- $\mathrm{B}$ signaling pathway and the inhibition of Akt could abort such cIAP2 enhancement [11]. Therefore, we here also investigated whether Akt inhibitor could affect the sensitivity of $\mathrm{HBV}+$ liver cancer cells to sorafenib. HepG2.215 cells were first treated with Akt inhibitor (10 $\mu \mathrm{M}$ MK-2206) and/or sorafenib for $48 \mathrm{~h}$, and then the expression of cleaved caspase 3 and cell viability was assessed. As shown in Fig. 4a, Akt inhibitor reduced the level of phosphorylated Akt (p-Akt) and the expression of cIAP2 in HepG2.215 cells. Furthermore, the combination of Akt inhibitor and sorafenib increased the level of cleaved caspase 3 (Fig. 4a). Similarly, the cell viability was also only reduced when cells were treated with the combination of Akt inhibitor and sorafenib (Fig. 4b). Taken together, these data here indicate that Akt inhibitor could partially restore sorafenib sensitivity in resistant liver cancer cells, probably through the downregulation of cIAP2 expression.

\section{Combination of lamivudine and sorafenib can reduce $\mathrm{HBV}+$ liver tumor growth in mouse model}

The in vivo efficacy of lamivudine in combination with sorafenib in suppressing liver cancer growth was also assessed in xenotransplantation mouse model. Similar to the data observed in cell lines, in HepG2-derived tumor, sorafenib treatment alone for two weeks significantly suppressed tumor growth, comparing to mock treatment group. However, in $\mathrm{HBV}+\mathrm{HepG}$.215-derived tumor, sorafenib alone did not shown apparent suppression in tumor volume reduction. Only did the combination of lamivudine and sorafenib significantly slowed down the tumor growth (Fig. 5, tumor volume and weight). During 


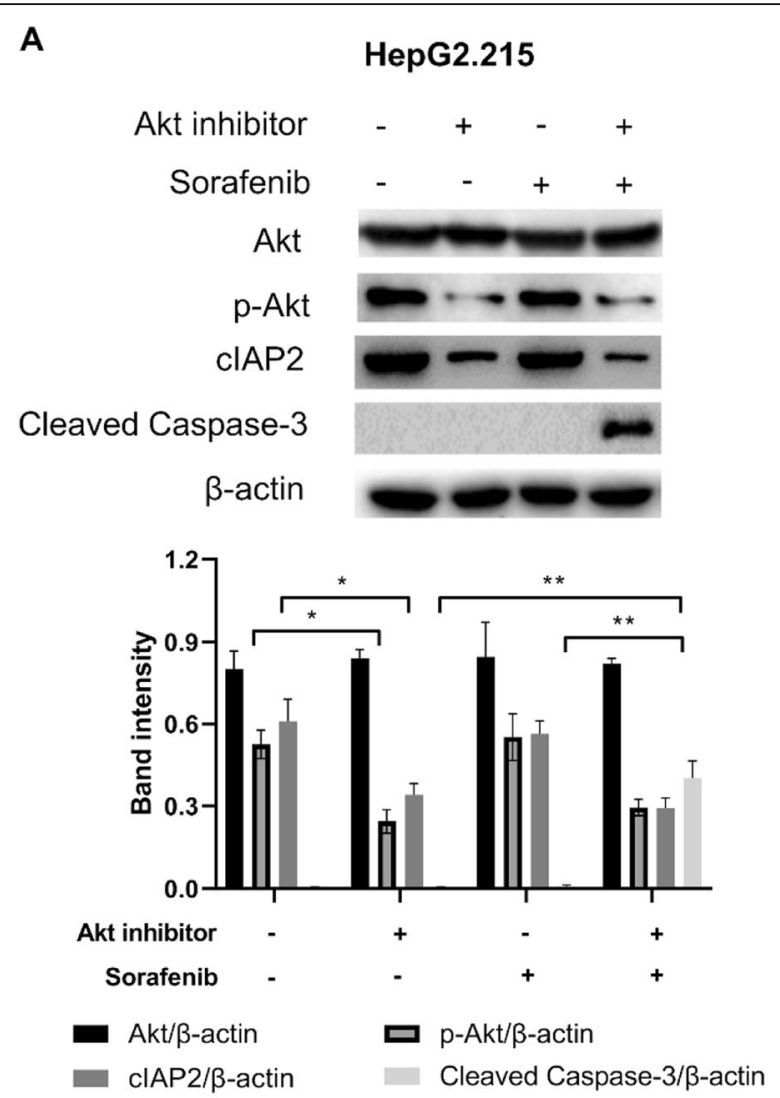

B

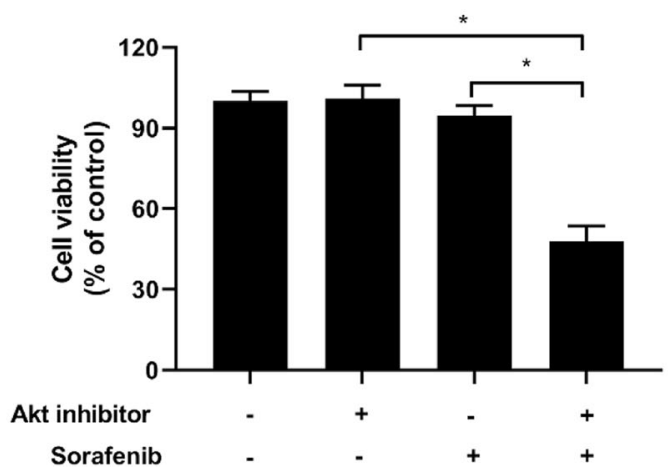

Fig. 4 Akt inhibitor treatment reduces cIAP2 expression and partially restores sorafenib sensitivity in liver cancer cell. a-b HepG2.215 cells were first treated with or without Akt inhibitor MK-2206, and then further treated with sorafenib. Twenty-four h post sorafenib treatment, a the expression of CIAP2 and cleaved caspase- 3 was determined by western blot, and $\mathbf{b}$ cell viability was assessed by MTT. For western blot, one representative data out of three is shown. For cell viability, data shown are mean \pm SD of three independent experiments. ns, not statistically significant; ${ }^{*}, p<0.05$; **, $p<0.01$

the treatment of sorafenib and/or lamivudine, mice body weight was also monitored, and no apparent changes were observed among different treatments (Fig. 5, mice weight). Together, the data here indicate that $\mathrm{HBV}+$
HepG2.215 cells are resistant to sorafenib and the cotreatment with anti-HBV drug lamivudine can restore the sensitivity of HepG2.215 cells to sorafenib and consequently reduce tumor growth (Fig. 6).

\section{Discussion}

With very limited treatment options, liver cancer, one of the most common cancers worldwide, is a big threat to the health of human and a huge economic burden to the society. The approved use of the first chemotherapeutic drug sorafenib has marked a new era in liver cancer treatment. Although sorafenib has improved overall survival of patients with advanced liver cancer, the tumor-response rate of sorafenib in liver cancer is low and also sorafenib resistance is observed, especially in HBV-infected patients. Therefore, to understand the mechanism underlying $\mathrm{HBV}$-induced sorafenib resistance in liver cancer is important for the optimization of sorafenib efficacy and/or development of new treatment strategies in liver cancer. Based on our previous finding that HBV promotes liver cancer cell survival by upregulation of cIAP2 expression via PI3K/Akt/NF- $\mathrm{B}$ signaling pathway, we, in the current study, further investigated whether HBV-induced cIAP2 expression was involved in sorafenib resistance in liver cancer. Our findings have shown that cIAP2 expression is involved in HBVinduced sorafenib resistance in liver cancer, and that the inhibition of HBV replication and cIAP2 upregulation Akt pathway could partially restore cancer cell sensitivity to sorafenib. This study provides not only a mechanism for the HBV-induced sorafenib resistance in liver cancer, but also a possible way to treat such condition.

Sorafenib, the so-far one of the few approved drug for patients with advanced liver cancer, is a multiple kinase inhibitor [15]. Sorafenib targets serine-threonine kinase Raf- 1 and some other tyrosine kinases like vascular endothelial growth factor receptors 1, 2 and 3, plateletderived growth factor receptor and fibroblast growth factor receptor $[15,16]$. Although phase III clinical trial showed that sorafenib increased survival rate, the rate of patients responding to sorafenib is actually very low (2$3 \%$ ), especially in HBV positive population [15-17]. Therefore, it is of great importance to understand the mechanism of sorafenib resistance, in order to develop effective strategies to cope these problems. A number of studies have shown that several pathways are involved in sorafenib resistance, including PI3K/Akt and JAK-STAT pathways, the activation of hypoxia-inducible pathways and the epithelial-mesenchymal transition [18-21]. However, the mechanism linking HBV infection and sorafenib resistance has not yet been clearly elucidated. Our previous study has shown that HBV infection could enhance the expression of cIAP2 via PI3K/Akt/NF-kB pathway in liver cancer [11]. In the current study, our 


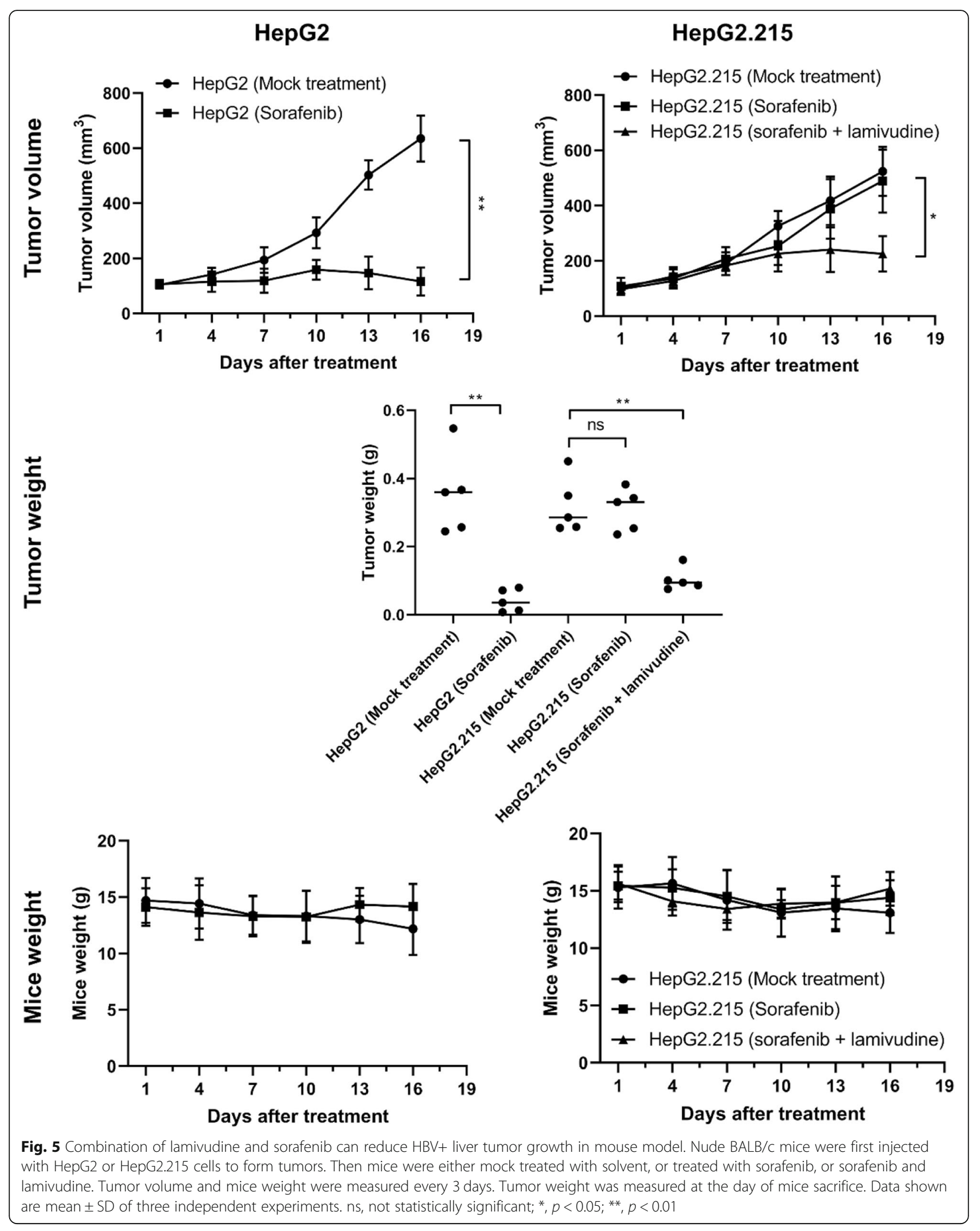




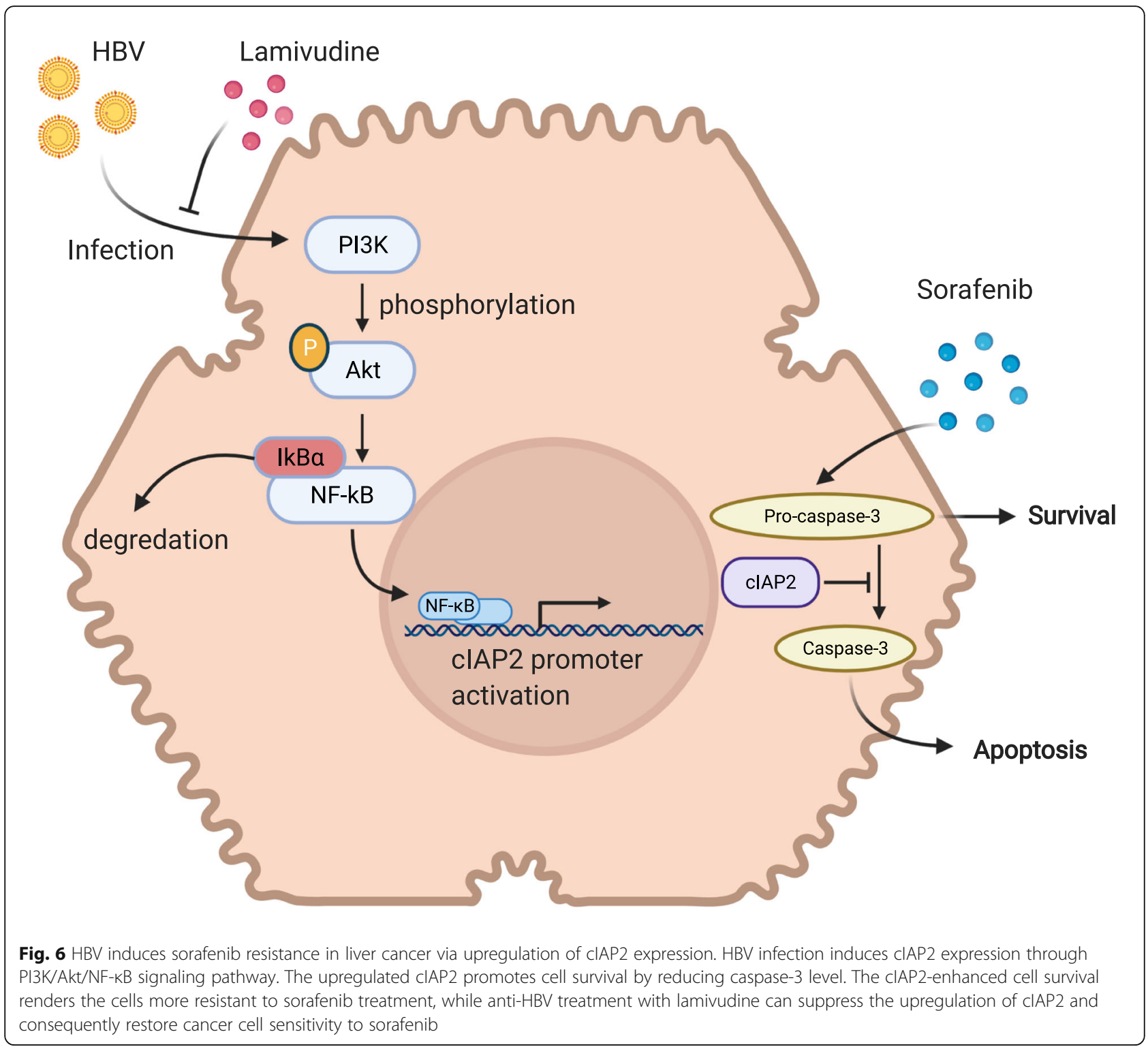

findings have further shown that HBV-induced cIAP2 upregulation is involved in sorafenib resistance. Moreover, inhibition of Akt, downregulation of cIAP2 and suppression of HBV replication can partially restore the liver cancer cell sensitivity to sorafenib, further implying the involvement of cIAP2, Akt pathway and HBV infection in the development of sorafenib resistance.

cIAP2 is a member of the inhibitor of apoptosis protein family, which sustains cell survival by inhibition of caspase activity [22-24]. The upregulation of cIAP2 has been observed in many forms of cancers, including liver cancer [25-27]. Our study here has indicated that the enhancement of cIAP2 expression by HBV infection contributes to the development of sorafenib resistance. However, we have also observed that when cIAP2 expression was downregulated via various means including cIAP2 knockdown, inhibition of Akt and HBV replication, the sorafenib resistance has only been partially overcome, indicating that other factors may also be involved in sorafenib resistance in HBV infected liver cancer. According to previous publications, HBV can interfere cell viability in several ways. Directly, HBV encodes a few oncogenesis genes like $\mathrm{HBx}$ and preS2/S, which promote cell survival and induce carcinogenesis [28-32]. Indirectly, HBV can increase the expression of many anti-apoptotic host genes like BCL-2, survivin and XIAP, which again support cell survival and inhibit cell death [33, 34]. Although it is beyond the scope of our current study, it would be interesting to investigate whether these alterations by HBV infection contribute to sorafenib resistance in liver cancer. 


\section{Conclusion}

Taken together, our findings have shown that cIAP2 expression is involved in $\mathrm{HBV}$-induced sorafenib resistance in liver cancer, and that the inhibition of HBV replication and cIAP2 upregulation Akt pathway could partially restore cancer cell sensitivity to sorafenib. This study provides not only a mechanism for the HBV-induced sorafenib resistance in liver cancer, but also a possible way to treat such condition.

\section{Abbreviations \\ HBV: Hepatitis B virus; CIAP2: Cellular inhibitor of apoptosis protein 2}

\section{Acknowledgements}

Not applicable.

\section{Authors' contributions}

SZ, NL, YY and JY designed the study. SZ, NL, YS, WC, QM, XY, JL, JZ, YY and $J Y$ performed and analysed the data. $S Z, N L$ and $J Y$ wrote the manuscript. All authors read and approved the final manuscript.

\section{Funding}

This work was supported by the National Natural Science Foundation of China (No:81960443; No: 81360338); and The Foundation of Jiangxi Provincial Health Department (No:20195422).

\section{Availability of data and materials}

The raw data supporting the conclusions of this manuscript will be made available by the authors, without undue reservation, to any qualified researcher.

\section{Declarations}

\section{Ethics approval and consent to participate}

All experimental protocols involving animals were reviewed and approved by the Ethical Review Committee of Second Affiliated Hospital of Nanchang University (Approval Number: NUH-A20180322) and performed in accordance with the local regulations.

\section{Consent for publication}

Not applicable.

\section{Competing interests}

The authors declare that they have no competing interests.

\section{Author details \\ ${ }^{1}$ Department of General Surgery, Second Affiliated Hospital of Nanchang University, 1 Minde Road, Nanchang, Jiangxi, China. ${ }^{2}$ Department of General Surgery, Jiangxi Provincial Children's Hospital, Nanchang, China. ${ }^{3}$ Department of Ultrasound, The Affiliated Hospital of Jiangxi University of Traditional Chinese Medicine, Nanchang, China. ${ }^{4}$ Department of Surgery, Jiangxi Provincial Cancer Hospital, Nanchang, China. ${ }^{5}$ Department of dermatology, Ili Kazakh Autonomous State Chinese Medicine Hospital, Xinjiang, Uygur Autonomous Region, China. ${ }^{6}$ Department of Oncology, The Affiliated

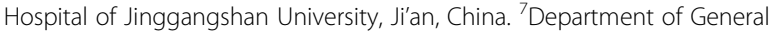 Surgery, Xinhua Hospital of Shanghai Jiao Tong University School of Medicine, 1665 Kongjiang Rd, Shanghai, China.}

\section{Received: 17 February 2021 Accepted: 16 March 2021}

Published online: 23 March 2021

\section{References}

1. Bray F, Ferlay J, Soerjomataram I, Siegel RL, Torre LA, Jemal A. Global cancer statistics 2018: Globocan estimates of incidence and mortality worldwide for 36 cancers in 185 countries. CA Cancer J Clin. 2018;68(6):394-424. https:// doi.org/10.3322/caac.21492.

2. Petrick JL, McGlynn KA. The changing epidemiology of primary liver cancer. Curr Epidemiol Rep. 2019:6(2):104-11. https://doi.org/10.1007/s40471-01900188-3.
3. Plummer M, de Martel C, Vignat J, Ferlay J, Bray F, Franceschi S. Global burden of cancers attributable to infections in 2012: a synthetic analysis. Lancet Glob Health. 2016;4(9):e609-16.

4. Perz JF, Armstrong GL, Farrington LA, Hutin YJ, Bell BP. The contributions of hepatitis $b$ virus and hepatitis $c$ virus infections to cirrhosis and primary liver cancer worldwide. J Hepatology. 2006;45(4):529-38.

5. Schweitzer A, Horn J, Mikolajczyk RT, Krause G, Ott JJ. Estimations of worldwide prevalence of chronic hepatitis b virus infection: A systematic review of data published between 1965 and 2013. Lancet. 2015;386(10003):1546-55.

6. Bruix J, Sherman M. Management of hepatocellular carcinoma: an update. Hepatology. 2011;53(3):1020-2. https://doi.org/10.1002/hep.24199.

7. Ghouri YA, Mian I and Rowe JH: Review of hepatocellular carcinoma: epidemiology, etiology, and carcinogenesis. J Carcinogen 16:1, 2017. PMID, DOl: https://doi.org/10.4103/jcar.JCar_9_16.

8. Wilhelm S, Carter C, Lynch M, Lowinger T, Dumas J, Smith RA, Schwartz B, Simantov R and Kelley S: Discovery and development of sorafenib: a multikinase inhibitor for treating cancer. Nat Rev Drug Discov 5(10): 835844, 2006. PMID, DOl: https://doi.org/10.1038/nrd2130, 2006.

9. Llovet JM, Ricci S, Mazzaferro V, Hilgard P, Gane E, Blanc JF, de Oliveira AC, Santoro A, Raoul JL, Forner A, Schwartz M, Porta C, Zeuzem S, Bolondi L, Greten TF, Galle PR, Seitz JF, Borbath I, Haussinger D, Giannaris T, Shan M, Moscovici M, Voliotis D and Bruix J: Sorafenib in advanced hepatocellular carcinoma. N Engl J Med 359(4): 378-390, 2008. PMID, DOI: https://doi.org/1 0.1056/NEJMoa0708857, 2008.

10. Cheng A-L, Guan Z, Chen Z, Tsao C-J, Qin S, Kim JS, Yang T-S, Tak WY, Pan H, Yu S, Xu J, Fang F, Zou J, Lentini G, Voliotis D, Kang Y-K. Efficacy and safety of sorafenib in patients with advanced hepatocellular carcinoma according to baseline status: Subset analyses of the phase iii sorafenib asia\&\#x2013;pacific trial. Eur J Cancer. 2012;48(10):1452-65. https://doi.org/1 0.1016/j.ejca.2011.12.006.

11. Lian J, Zou Y, Huang L, Cheng H, Huang K, Zeng J and Chen L: Hepatitis b virus upregulates ciap2 expression via pi3k/akt/nf-kb signaling pathway in liver cancer. Oncology letters In press 2019. PMID, DOI:

12. Hu K, Fu M, Guan X, Zhang D, Deng X, Xiao Y, Chen R, Liu H and Hu Q: Penton base induces better protective immune responses than fiber and hexon as a subunit vaccine candidate against adenoviruses. Vaccine 36(29): 4287-4297, 2018. PMID, DOl: https://doi.org/10.1016/j.vaccine.2018.05.118, 2018.

13. Zhao R, Wang T-Z, Kong D, Zhang L, Meng H-X, Jiang Y, Wu Y-Q, Yu Z-X and Jin X-M: Hepatoma cell line hepg2.2.15 demonstrates distinct biological features compared with parental hepg2. World J Gastroenterol 17(9): 11521159, 2011. PMID, DOI: https://doi.org/10.3748/wjg.v17.i9.1152, 2011.

14. Chan DW and $\mathrm{Ng}$ IO: Knock-down of hepatitis $b$ virus $x$ protein reduces the tumorigenicity of hepatocellular carcinoma cells. J Pathol 208(3): 372-380, 2006. PMID, DOI: https://doi.org/10.1002/path.1901, 2006.

15. Llovet JM, Ricci S, Mazzaferro V, Hilgard P, Gane E, Blanc JF, De Oliveira AC, Santoro A, Raoul JL, Forner A, Schwartz M. Sorafenib in advanced hepatocellular carcinoma. N Engl J Med. 2008;359(4):378-90.

16. Chen K-F, Chen H-L, Tai W-T, Feng W-C, Hsu C-H, Chen P-J, Cheng A-L. Activation of phosphatidylinositol 3-kinase/akt signaling pathway mediates acquired resistance to sorafenib in hepatocellular carcinoma cells. J Pharmacol Exp Ther. 2011:337(1):155-61.

17. Casadei Gardini A, Frassineti GL, Foschi FG, Ercolani G and Ulivi P: Sorafenib and regorafenib in hbv- or hcv-positive hepatocellular carcinoma patients: analysis of resorce and sharp trials. Digest Liver Dis 49(8): 943-944, 2017. PMID, DOI: https://doi.org/10.1016/j.dld.2017.04.022, 2017.

18. van Malenstein $H$, Dekervel J, Verslype C, Van Cutsem E, Windmolders $P$, Nevens F and van Pelt J: Long-term exposure to sorafenib of liver cancer cells induces resistance with epithelial-to-mesenchymal transition, increased invasion and risk of rebound growth. Cancer Lett 329(1): 74-83, 2013. PMID, DOI: https://doi.org/10.1016/j.canlet.2012.10.021, 2013.

19. Heqing $Y$, Bin L, Xuemei $Y$ and Linfa L: The role and mechanism of autophagy in sorafenib targeted cancer therapy. Crit Rev Oncol Hematol 100: 137-140, 2016. PMID, DOI: https://doi.org/10.1016/j.critrevonc.2016.02. 006, 2016.

20. Zhu YJ, Zheng B, Wang HY and Chen L: New knowledge of the mechanisms of sorafenib resistance in liver cancer. Acta Pharmacol Sin 38(5): 614-622, 2017. PMID: PMC5457690, DOI: https://doi.org/10.1038/aps.2 $017.5,38,5,614,622$.

21. Witt-Kehati D, Fridkin A, Alaluf MB, Zemel R, Shlomai A. Inhibition of pmapk14 overcomes resistance to sorafenib in hepatoma cells with hepatitis b virus. Transl Oncol. 2018;11(2):511-7. 
22. Roscioli E, Hamon R, Ruffin RE, Grant J, Hodge S, Zalewski P and Lester S: Birc3 single nucleotide polymorphism associate with asthma susceptibility and the abundance of eosinophils and neutrophils. J Asthma 54(2): 116-124, 2017. PMID, DOl: https://doi.org/10.1080/02770903.2016.1196371, 2017.

23. Jiang X, Li C, Lin B, Hong H, Jiang L, Zhu S, Wang X, Tang N, Li X, She F and Chen Y: Ciap2 promotes gallbladder cancer invasion and lymphangiogenesis by activating the nf-kappab pathway. Cancer Sci 108(6): 1144-1156, 2017. PMID: PMC5480088, DOl: https://doi.org/10.1111/cas.13236, $108,6,1144,1156$

24. Wang D, Berglund AE, Kenchappa RS, MacAulay RJ, Mule JJ and Etame AB: Birc3 is a biomarker of mesenchymal habitat of glioblastoma, and a mediator of survival adaptation in hypoxia-driven glioblastoma habitats. Sci Rep 7(1): 9350, 2017. PMID: PMC5570925, DOl: https://doi.org/10.1038/s41 598-017-09503-8, 7, 1, 9350.

25. Wu HH, Wu JY, Cheng YW, Chen CY, Lee MC, Goan YG and Lee H: Ciap2 upregulated by e6 oncoprotein via epidermal growth factor receptor/ phosphatidylinositol 3-kinase/akt pathway confers resistance to cisplatin in human papillomavirus 16/18-infected lung cancer. Clin Cancer Res 16(21): 52005210, 2010. PMID, DOl: https://doi.org/10.1158/1078-0432.Ccr-10-0020, 2010.

26. Gill C, Dowling C, O'Neill AJ and Watson RW: Effects of ciap-1, ciap-2 and xiap triple knockdown on prostate cancer cell susceptibility to apoptosis, cell survival and proliferation. Mol Cancer 8: 39, 2009. PMID: PMC2706796, DOl: https://doi.org/10.1186/1476-4598-8-39, 8, 1, 39.

27. Wang $Q$, Wang $X$ and Evers $B M$ : Induction of ciap-2 in human colon cancer cells through pkc delta/nf-kappa b. J Biol Chem 278(51): 51091-51099, 2003. PMID, DOl: https://doi.org/10.1074/jbc.M306541200, 2003.

28. Wang HC, Huang W, Lai MD and Su IJ: Hepatitis b virus pre-s mutants, endoplasmic reticulum stress and hepatocarcinogenesis. Cancer Sci 97(8): 683688, 2006. PMID, DOI: https://doi.org/10.1111/j.1349-7006.2006.00235.x, 2006.

29. Menolfi D, Delamarre A, Lengronne A, Pasero $P$ and Branzei D: Essential roles of the smc5/6 complex in replication through natural pausing sites and endogenous DNA damage tolerance. Mol Cell 60(6): 835-846, 2015. PMID: PMC4691243, DOl: https://doi.org/10.1016/j.molcel.2015.10.023, 60, 6, $835,846$.

30. Tropberger P, Mercier A, Robinson M, Zhong W, Ganem DE and Holdorf M: Mapping of histone modifications in episomal hbv cccdna uncovers an unusual chromatin organization amenable to epigenetic manipulation. Proc Natl Acad Sci U S A 112(42): E5715-E5724, 2015. PMID: PMC4620859, DOI: https://doi.org/10.1073/pnas.1518090112, 112, 42, E5715, E5724.

31. Ringelhan $\mathrm{M}, \mathrm{O}^{\prime} \mathrm{C}$ Connor T, Protzer $\mathrm{U}$ and Heikenwalder $\mathrm{M}$ : The direct and indirect roles of hbv in liver cancer: prospective markers for hcc screening and potential therapeutic targets. J Pathol 235(2): 355-367, 2015. PMID, DOI: https://doi.org/10.1002/path.4434, 2015.

32. Lau CC, Sun T, Ching AK, He M, Li JW, Wong AM, Co NN, Chan AW, Li PS, Lung RW, Tong JH, Lai PB, Chan HL, To KF, Chan TF and Wong N: Viralhuman chimeric transcript predisposes risk to liver cancer development and progression. Cancer Cell 25(3): 335-349, 2014. PMID, DOI: https://doi.org/10.1 016/j.ccr.2014.01.030, 2014.

33. Chao CC: Inhibition of apoptosis by oncogenic hepatitis $b$ virus $x$ protein: Implications for the treatment of hepatocellular carcinoma. World J Hepatol 8(25): 1061-1066, 2016. PMID: PMC5026997, DOI: https://doi.org/10.4254/wjh. v8.i25.1061, 8, 25, 1061, 1066 .

34. Chang CS, Huang SM, Lin HH, Wu CC, Wang CJ. Different expression of apoptotic proteins between hbv-infected and non-hbv-infected hepatocellular carcinoma. Hepatogastroenterology. 2007;54(79):2061-8.

\section{Publisher's Note}

Springer Nature remains neutral with regard to jurisdictional claims in published maps and institutional affiliations.

Ready to submit your research? Choose BMC and benefit from:
- fast, convenient online submission
- thorough peer review by experienced researchers in your field
- rapid publication on acceptance
- support for research data, including large and complex data types
- gold Open Access which fosters wider collaboration and increased citations
- maximum visibility for your research: over 100M website views per year
At BMC, research is always in progress.
Learn more biomedcentral.com/submissions

